\title{
AQUÍ ESTÁ TODO: RATAS, EVOLUCIÓN Y HONOR. CUADRILLAS JUVENILES Y BARRIO EN COSTA RICA. ONÉSIMO GERARDO RODRÍGUEZ AGUILAR. SAN JOSÉ, COSTA RICA: EDITORIAL ARLEKÍN, 2017. 328 PÁGINAS
}

Javier Antonio Torres Vindas

Recibido: 11/05/2017 Aceptado: 18/05/2017

En el 2017, la Editorial Arlekín (San José, Costa Rica) publica el libro Aquí está todo: Ratas, evolución y honor. Cuadrillas juveniles y barrio en Costa Rica, del Dr. Onésimo Gerardo Rodríguez Aguilar, el cual es fruto de su trabajo doctoral desarrollado en la Universidad Autónoma Metropolitana (México); Unidad Iztapalapa en posgrado en Ciencias Antropológicas.

¿Es un trabajo como otros? A mi juicio no, por lo que con entusiasmo les comparto mi reflexión tras leer este generoso y bien elaborado texto de abstracción teórica, investigación empírica, pasión científica, rigurosidad académica e imaginación etnográfica. Inicio este viaje a Ítaca, con las palabras del Dr. Mario Zúñiga (quien prologa el libro):

Efectivamente, el trabajo sin dejar de ser riguroso insta en cada página a sumergirnos, con su autor, en la piel de los muchachos de Guararí, en su hábitat, en su ser-estar-sentir-actuar-representar desde ese locus complejo y no siempre asible de la otredad: este asunto de "conversar" con muchachos apostados en varias de las esquinas del barrio, no era tan sencillo. Era complicado no porque no existieran, sus humanidades estaban físicamente alli, lo dificultoso era resolver la forma de "acercamiento etnográfico", procedimiento caro a la tradición antropológica. Los jóvenes estaban ahi mismo, ante mí y sin embargo tan lejos. ${ }^{1}$

¿Otredad u otredades? Efectivamente, lo más armonioso del texto es que está habitado de manera muy creativa por muchas "voces": la del autor, la de sus interlocutores de Guararí o "cuadrillas", las de autores con quienes dialoga (académicos, poetas, ensayistas, etc.), las omisas (tutores, compañeros de doctorado, amigos, camaradas, etc.). Así, se logra una "polifonía etnográfica" atractiva y novedosa (parafraseando a Bajtín), que permite una lectura dúctil, atenta, seductora y reflexiva, la cual nos sumerge e invita a un diálogo-lectura-comprensión; es su contrapunto. Más importante aún, y no siempre fácil de lograr, es el hecho de que el texto muestra a su autor: lo escrito como medio para dialogar con el Dr. Rodríguez, con sus ideas, su originalidad, en su toma de postura, sus apuestas; respecto de los programadores de sentido de su estudio "Aquí está todo: ratas, evolución y honor". 
Además, el texto unifica el sentido del mundo que los jóvenes dan a Guararí, en tanto soporte espacial, relacional, axiológico e histórico. Un locus "el barrio" y una categoría que intenta romper la criminalización de los jóvenes "cuadrillas", al asir su existencia y reflexionar sobre ella. Al respecto cabe subrayar que

En Costa Rica y Latinoamérica, "cuadrilla" es un término que no ha sido incluido en la agenda académica; se han desarrollado intentos investigativos desde la noción "pandillas" que, a diferencia de "cuadrilla", no logra incorporar el carácter barrial, laboral y de clase, dimensiones que son trascendentales en la composición de estos grupos... Este acercamiento con chicos en cuadrillas intenta trascender esas visiones irreflexivas que tienden a culpar a los y las jóvenes como si fueran individuos separados de las construcciones sociales y nacionales, como si su presencia estuviera en el exilio de lo permitido; la intención es contextualizar sus actividades y tratar de explicar sus acciones más allá del tradicional enfoque mediático (26-27).

¿Cómo nos acercamos a esas cuadrillas y ese locus? Para tal efecto, se han dispuesto los siguientes contenidos. Un prólogo cuyo título es "Hasta lloviendo estamos ahí" por el Dr. Mario Zúñiga, quien nos presenta aspecto nodales del trabajo de Rodríguez, especialmente lo novedoso de su apuesta etnográfica. Por su parte, en la Introducción, Rodríguez habla de sus motivos de investigación, de los procesos de ingreso y de la construcción de confianza con los jóvenes de Guararí en sus esquinas y en su vida cotidiana, con el fin de observarlos y conversar con ellos.

Aunado a esto, nos presentan los principales antecedentes de investigación en los cuales se pueden encontrar continuidades y rupturas de la tradición etnográfica sobre la juventud, junto a inquietudes epistemológicas, éticas e interpretativas de este proceso de investigación. Todo el texto es presentado en primera persona al referirse al investigador en un proceso de "objetivación del sujeto objetivante".

El texto continúa en cinco unidades temáticas o partes (cada una subdividida en capítulos). La primera "'Los de Guararí, algunas cifras y la vida cotidiana barrial" despliega datos de contextualización sociodemográfica e histórica de la entronización de Guararí (lógica barrial) en su contexto local más amplio que le contrasta Heredia (lógica ciudad). En este apartado llama la atención dos acercamientos conceptuales (esfuerzo sostenido de la primera a la última página) sobre la ciudad narcisista y la vida cotidiana barrial. En otras palabras, se trata de orientar:

Precisiones acerca de las condiciones de los muchachos integrantes de cuadrillas, intentaba mostrar la composición sociocultural de estas agrupaciones, enfocándome en aspectos como la familia, educación y actividades económicas, entre otros. La intención era ubicar a estos sujetos en tanto actores participantes de realidades complejas y heterogéneas, en un escenario barrial cargado de contrastes y exceso (305). 
La segunda parte, denominada "De jóvenes, pandillas y cuadrillas", se profundiza y decantan las apuestas ontológicas, epistemológicas y teóricas [interpretativas y explicativas], del Dr. Rodríguez; es decir el núcleo teórico del objeto de estudio. Empieza la discusión sobre jóvenes "a-normales" -siempre díscolos e inadaptados desde la mirada adultocéntrica y prejuiciosa-, se explaya en definir y diferenciar pandilla de cuadrilla - "la vida de uno"-, terminando con la disputa del sentido de la "ley" para las cuadrillas y los límites desde ese sentido "emic" y ¿subalterno?, respecto a la ley, lo normal, lo cotidiano.

En la tercera parte, titulada "La construcción sociohistórica del barrio I. La juventud añorada", se aborda la génesis y estructura del espacio y de las relaciones sociales de quienes habitan Guararí. Como todo recuerdo, este se llena de vacíos, olvidos, retazos, interpretaciones, ensoñaciones, aspiraciones y miradas utópicas sobre ese pasado. Al respecto, desatacan las reflexiones sobre las invasiones (¿bárbaras?), la inexistencia, lo superfluo, lo fundacional, los héroes y antihéroes de los momentos gestacionales, el eje de lo político y las decadencias primigenias.

Más adelante, el texto continúa con la sección "La construcción sociohistórica del barrio II. La juventud proscrita", en donde arribamos a la construcción de fronteras reales, imaginarias, efectivas de Guararí y su entorno. En este punto resulta importante subrayar la autocontención de los jóvenes en su barrio, en su cotidianidad y en su cuadrilla. Esta no es una prisión real o imaginaria, sino un modo de ser y estar; un ethos, una praxis. Se comparten experiencias, nociones, aspiraciones, miedos, y se construye un "lenguaje" propio del grupo: nuevos invasores, jóvenes como víctimas, vacío, juventud violenta. Si bien, la voz de los jóvenes es la que el autor desea abordar y desde ella reconstruir sus mundo simbólicos, realmente es Rodríguez (etic) quien organiza, orienta e interpreta.

De entre todas las figuras destaco el intertexto de Guararí-Guernica. Es decir, la producción social, histórica e institucional de lo excluyente, del hueco, de las contradicciones sistémicas, las no simbolizadas. En Guernica, la brutalidad de la guerra moderna que reconoce al otro. En Guararí el reclamo hacia la gestión gubernamental y la matriz sociocultural del capitalismo contemporáneo. Tal como afirma Rodríguez “¿es acaso el reclamo que Guararí y su gente pudiera manifestar al modelo social, económico, político y cultural impuesto por los agentes anónimos del capitalismo actual, y finalmente a la sociedad que se torna inquisidora en sus perspectivas hacia esta comunidad y sus residentes?" (227).

Continua el texto con "Etnografiando al ethos cuadrillero" que nos sumerge en las herramientas de una praxis etnográfica, sobre la cual cabe preguntarse ¿qué hacer con los datos y cómo estos iluminan contenidos?, ¿cómo observar aspectos no observables de forma directa en la realidad?, ¿cómo observar conceptos abstractos de la realidad sociohistórica y subjetiva en la vida cotidiana? En el caso acá tratado se trata de un ethos que nos habla de los vínculos de confianza, reconocimiento, acompañamiento, 
cooperación entre jóvenes, de sus estrategias de producción y reproducción cotidiana, de sus códigos de alianza y lealtad, sobre una ética que se manifiesta en estéticas que reafirman la primera y de una actitud de "maldad" como como mecanismo de protección.

Finalmente, las conclusiones del texto discuten aspectos centrales como la construcción barrial de las cuadrillas de jóvenes en Guararí y la función instituyente de las violencias. Así, el autor trata de interpelarnos en nuestras formas éticas, políticas y estéticas de pensar-sentir las juventudes, he aquí el reto y el compromiso del texto.

Para finalizar este breve viaje, suscribo las palabras del Dr. Zúñiga: "es lo que muestra finalmente este libro, las líneas de un rostro laberíntico, sombrío y triste, que hemos dibujado a la orilla del desarrollo social de nuestro país y que insistimos en negar mediante estigmas y abulia institucional" (19).

\section{Nota}

1 Guararí, es una comunidad ubicada en el distrito de San Francisco del cantón de Heredia en la provincia de Heredia en Costa Rica, fruto de invasión a la finca La Esperanza en 1986.

Javier Antonio Torres Vindas. Costarricense, obtuvo el Doctorado en Investigación en Ciencias Sociales en la Facultad Latinoamericana de Ciencias Sociales, Sede Académica México. Posee el grado de Bachiller y Maestría en Sociología por la Universidad de Costa Rica. En la actualidad se desempeña como docente en Escuela de Sociología de Universidad de Costa Rica. Asimismo ha colaborado en UNED, UNA, ICAP y UNAH. Sus áreas de investigación son epistemología y metodología de las ciencias sociales, sociología electoral, sociología relacional, análisis de redes sociales, análisis ideológico de discurso y análisis de coyuntura.

Contacto: socioarte@gmail.com

ORCID: 0000-0002-0130-5979 